PAPER

\title{
Social deprivation and adult head injury: a national study
}

\section{Dunn, J Henry, D Beard}

J Neurol Neurosurg Psychiatry 2003;74:1060-1064

See end of article for authors' affiliations

......................

Correpondence to: $\mathrm{Mr} \mathrm{LT}$ Dunn, Senior Lecturer in

Neurosurgery, Department of Neurosurgery, Institute of Neurological Sciences, Southern General Hospital, Glasgow G51 4TF, UK: Itd 1x@udcf.gla.ac.uk

Received

20 November 2002

Accepted 6 March 2003 measures of social deprivation, mechanisms of Objectives: To establish the association between measures of soc
injury, patterns of care, and outcome following closed head injury. Methods: All Scottish adult A\&E attendees with closed head injury (AIS Head $\geqslant 3$ ) between July 1996 and December 2000 were studied.

Results: Trauma was more common in individuals from more deprived areas. Within the trauma population head injury was relatively more common in patients from deprived areas; these individuals were more likely to sustain an isolated head injury as a result of an assault. Admission GCS was higher and normal physiology (as assessed by the RTS) was more common in individuals from more deprived areas. Recorded co-morbidity was similar between the two groups with the exception of a history of alcohol or substance abuse which was more common among patients from more deprived areas. Similar proportions of patients from more deprived and less deprived areas were transferred to the Regional Neurosurgical Centre. For patients who were transferred directly from A\&E, time to neurosurgical theatre was similar for both groups. Length of hospital and ITU stay was less in patients from more deprived areas. After adjusting for known predictors of outcome using logistic regression analysis, there was no significant difference in mortality between patients from more deprived and less deprived areas.

Conclusions: Residing in a more deprived area is not associated with increased mortality from head injury among adults in Scotland. It is associated with different patterns of injury and a different process of care following presentation to hospital.
$\mathrm{T}$ he relation between socioeconomic status and many different aspects of health is well established..$^{1-3}$ It is also recognised that social deprivation can affect patterns of injury and outcome after trauma. ${ }^{4-6}$ The interaction between socioeconomic factors and outcome after head injury in adults has received relatively less attention, ${ }^{7-9}$ although head injury is an important determinant of mortality after trauma. ${ }^{10}$ Deaths from trauma have been estimated to be responsible for more years of life lost in males under the age of 65 in the USA, Japan, and several European countries than cardiac and cerebrovascular disease or cancer. ${ }^{11}$ Knowledge of the importance of socioeconomic factors in head injury is therefore likely to be of value in health service provision and the targeting of preventive measures.

We have used a prospectively collected national database of trauma cases ${ }^{12}$ to investigate the relation between socioeconomic factors, mechanisms of injury, process of care, and outcome in adults with head injury using deprivation measures calculated on the basis of domicile postcodes. ${ }^{13}$

\section{METHODS}

\section{The Scottish Trauma Audit Group}

The Scottish Trauma Audit Group (STAG) was established in 1991 to observe and improve the management of seriously injured patients in Scottish hospitals. ${ }^{12}$ STAG collects data on the entire episode of in-patient care, from prehospital intervention to discharge, postmortem examination, or the end of a three month acute in-patient stay. Information is collected on injured patients who are admitted for at least three days or who die within hospital. National data capture rate is estimated to be in excess of $94 \%$ and the hospitals included in STAG receive in excess of $98 \%$ of major trauma in Scotland. Patients aged over 65 who have sustained an isolated fracture of the neck of femur or pubic ramus are excluded from the audit to improve the match with the American reference database. ${ }^{14}$ Those patients who are declared dead within 15 minutes of arrival in the accident and emergency (A\&E) department (and who have no interventions undertaken) are also excluded, as are children of less than 13 years of age. Patients who are transferred to another hospital, either directly from A\&E departments or from a ward, are monitored by the regional coordinators in the receiving centres.

\section{Head injury}

All patients in the study had their injuries scored by a single individual trained in using Abbreviated Injury Scale (AIS) methodology. ${ }^{15}$ In this study, head injury (HI) was defined as any patient with an AIS score of 3 or greater for the head component of the score. An isolated head injury was any patient with a head injury and no extracranial injury as coded by AIS score.

\section{Deprivation scores}

Domicile postcodes were recorded on admission, if possible, or subsequently obtained by the local audit coordinators. On the basis of this postcode, patients were assigned a deprivation category from 1 (least deprived) to 7 (most deprived) using the Carstairs and Morris index of deprivation. ${ }^{13}$ This is a widely accepted definition of socioeconomic deprivation based on four variables: overcrowding, male unemployment, low social class, and car ownership. This index has been shown to correlate well with a range of health measures. ${ }^{16}$ The Carstairs and Morris index was originally developed in the 1980s using 1981 census data and has recently been updated by McLoone

Abbreviations: A\&E, accident and emergency; AIS, Abbreviated Injury Scale; GCS, Glasgow Coma Scale; HI, head injury; ITU, intensive therapy unit; RTA, road traffic accident; RTS, Revised Trauma Score; STAG, Scottish Trauma Audit Group 
Table 1 Scottish general and STAG trauma populations

\begin{tabular}{lrllll}
\hline & \multicolumn{2}{l}{ Less deprived } & & \multicolumn{2}{l}{ More deprived } \\
\cline { 2 - 3 } \cline { 5 - 6 } & $\mathrm{n}$ & $\%$ & & $\mathrm{n}$ & \multicolumn{1}{l}{$\%$} \\
\hline STAG & 19651 & 78.8 & & 5276 & 21.2 \\
Scotland & 4088285 & 82.2 & & 887495 & 17.8 \\
\hline
\end{tabular}

$95 \% \mathrm{Cl}$ for difference in proportion of population from more deprived areas $=2.82 \%$ to $3.84 \%$.

Source: Information and Statistics Division (ISD) Scotland.

using 1991 census information. ${ }^{1}$ Based on their Carstairs deprivation category, patients were divided into two groups: less deprived (categories 1-5) and more deprived (categories 6 and 7). ${ }^{17}$ For a small number of patients, only the first four digits of the postcode were available. Although it was not always possible to assign a deprivation category for these patients, in the majority of cases, it was possible to assign these patients to a deprivation group (less deprived or more deprived).

\section{Statistics}

Differences between categorical variables were analysed using $\chi^{2}$ tests and differences in non-parametric continuous variables were analysed using Mann-Whitney U tests. One way ANOVA and $95 \%$ confidence intervals were used to determine differences in continuous time based variables. Logistic regression was used to determine if social deprivation had any independent effect on mortality following trauma after controlling for other known predictors of outcome.

Preanalysis was carried out to determine if the cohort of patients for whom a deprivation group could not be assigned differed from that with an assigned deprivation group. Then, patients sustaining a head injury were compared with respect to whether they came from a more (Carstairs deprivation categories 6 and 7) or less (Carstairs deprivation categories 1-5) deprived area. Analysis focused on a number of key demographic, process, and outcome measures.

\section{RESULTS}

In the period between July 1996 and December 2000, 28208 patients were entered onto the STAG database. Deprivation groups were assigned to $88.4 \%$ (24 927) of patients for whom valid Scottish postcodes were available. Postcodes were not recorded for $5.8 \%$ (1642) of patients. A further $4.5 \%$ (1266) of patients had non-Scottish postcodes and $1.3 \%$ (373) of patients had provided postcodes for which deprivation scores could not be assigned.
Initial analysis showed that the STAG population had a lower proportion of patients from less deprived areas and a higher proportion of patients from more deprived areas than the Scottish population as a whole (table 1).

\section{Analysis of missing deprivation score}

Patients for whom a valid deprivation group could be assigned were analysed to determine if their case mix differed significantly from those for whom a deprivation group could not be assigned. Those without deprivation groups were significantly younger, more likely to be male, more likely to have sustained penetrating trauma, and more likely to have been injured in a road traffic accident (RTA), assault, or high fall (table 2). They were more likely to have an abnormal Revised Trauma Score (RTS < 7.8408) and more likely to be seriously injured (ISS 16-75). In terms of outcome, those for whom no deprivation group could be assigned were more likely to die.

\section{Head injuries}

Over the study period, 4774 (18\%) patients meeting the STAG entry criteria sustained a head injury (AIS $\geqslant 1$ ). Of these, 3113 patients sustained a head injury with AIS score $\geqslant 3$. Those for whom no deprivation category could be assigned were no more or less likely to sustain a head injury (AIS $\geqslant 3$ ) (deprivation category $2932(11.8 \%)$, no deprivation category 181 $\left.(11 \%), \chi^{2}=0.744, p=0.388\right)$. It is possible that patients with a head injury and missing postcodes are more likely to be from more deprived areas. We therefore assumed that all patients with missing postcodes were from more deprived areas and investigated differences in crude mortality. This assumption did not significantly affect mortality (proportion alive: less deprived $78 \%$ (1617), more deprived $77.3 \%$ (803); 95\% CI $-2.4 \%$ to $3.8 \%)$. Patients with missing postcodes were excluded from further analysis.

Patients classified as residing in more deprived areas had a higher than expected incidence of head injury than those classed as from less deprived areas (16.3\% (858) v 10.6\% (2074); $95 \%$ CI for difference $5.4 \%$ to $8.0 \%$; table 3 ).

The 2932 remaining patients with a deprivation category assigned and a head injury were investigated to determine if there were differences between those from more deprived areas $(858,29.3 \%)$ and those from less deprived areas (2074, $70.7 \%)$.

\section{Patient characteristics}

There was no significant difference in age between the two groups (mean age 44.5 years), but patients from more deprived areas were more likely to be male $(81.9 \% \vee 75.6 \%$, $\left.\chi^{2}=13.9, p=0.000\right)$. Forty eight patients $(1.6 \%)$ had

Table 2 Differences between those with deprivation categories and those without deprivation categories

\begin{tabular}{|c|c|c|c|}
\hline & $\begin{array}{l}\text { Valid deprivation code } \\
\text { category }(n=24927)\end{array}$ & $\begin{array}{l}\text { No valid deprivation code } \\
\text { category ( } n=1642)\end{array}$ & $\mathrm{p}$ \\
\hline Median age & $50 y$ & $43 y$ & 0.000 \\
\hline$\%$ male & 57.2 & 65.5 & 0.000 \\
\hline$\%$ penetrating trauma & 5.4 & 6.9 & 0.01 \\
\hline$\%$ RTA & 22 & 30.2 & 0.000 \\
\hline$\%$ assault & 8.9 & 10.7 & 0.022 \\
\hline$\%$ high fall & 9.2 & 11.1 & 0.01 \\
\hline$\%$ low fall & 48.3 & 35.1 & 0.000 \\
\hline$\%$ RTS $<7.8408$ & 11.4 & 17.4 & 0.000 \\
\hline$\%$ ISS $>15$ & 13.8 & 17.5 & 0.000 \\
\hline$\%$ death in A\&E & 0.7 & 5.0 & 0.000 \\
\hline$\%$ dead in hospital & 4.1 & 8.8 & 0.000 \\
\hline$\%$ head injury (AIS $\geqslant 3$ ) & 11.8 & 11.0 & 0.384 \\
\hline
\end{tabular}

RTA, road traffic accident; RTS, Revised Trauma Score; ISS, Injury Severity Score; AIS, Abbreviated Injury Score. 
Table 3 Distribution of head injury (AIS $\geqslant 3$ ) within deprivation groups

\begin{tabular}{|c|c|c|c|c|c|}
\hline & \multicolumn{2}{|c|}{$\begin{array}{l}\text { Less deprived } \\
\text { (Carstairs 1-5) }\end{array}$} & \multicolumn{2}{|c|}{$\begin{array}{l}\text { More deprived } \\
\text { (Carstairs } 6 \text { and 7) }\end{array}$} & \multirow[b]{2}{*}{ Total } \\
\hline & $\mathrm{n}$ & $\%$ & $\mathrm{n}$ & $\%$ & \\
\hline $\mathrm{HI}$ & 2074 & 10.6 & 858 & 16.3 & 2932 \\
\hline $\mathrm{No} \mathrm{HI}$ & 17577 & 89.4 & 4418 & 83.7 & 21995 \\
\hline Total & 19651 & & 5276 & & 24927 \\
\hline
\end{tabular}

$95 \% \mathrm{Cl}$ for difference in proportion of patients with $\mathrm{HI}$ from more deprived areas $=5.4 \%$ to $8.0 \%$

AIS, Abbreviated Injury Score; HI, head injury.

sustained a penetrating head injury. In terms of mechanism of injury, patients from the more deprived group were more likely to have been assaulted $\left(28.6 \% \vee 15.1 \%, \chi^{2}=70.8\right.$, $\mathrm{p}=0.000)$. Patients from the "less deprived" group were more likely to have been involved in an RTA $(37.3 \% v 20.4 \%$, $\left.\chi^{2}=79.4, p=0.000\right)$ or fallen from a height $(14.0 \% v 10.3 \%$, $\left.\chi^{2}=7.4, p=0.007\right)$. Median Glasgow Coma Scale (GCS) was higher in patients from more deprived areas (GCS $13 v$ GCS 12, $\mathrm{U}=830974, \mathrm{p}=0.004$ ).

Although patients in the more deprived group were more likely to have sustained an isolated head injury $(83.8 \% \mathrm{v}$ $72.2 \%, \chi^{2}=44.1 \mathrm{p}=0.000$ ) and had a higher median GCS, there was no significant difference in the severity of head injury (as assessed using the AIS; median AIS $=4$ ) between more deprived and less deprived patients. The proportion of patients with abnormal physiology (revised trauma score $<7.8408)$ was lower in the "more deprived" group $(47.7 \%)$ than in the "less deprived group" $\left(53.6 \%, \chi^{2}=8.6, \mathrm{p}=0.004\right)$.

\section{A\&E management}

More deprived patients were more likely to self present to A\&E $\left(14.2 \% \vee 8.3 \%, \chi^{2}=23.6, p=0.000\right)$, more likely to present outside normal working hours (78.4\% $v 73.8 \%$, $\chi^{2}=7.1, p=0.009$ ) and less likely to be triaged to the resuscitation room on arrival in the department $(62.3 \% \vee 71.5 \%$, $\left.\chi^{2}=24.3, p=0.000\right)$. Within the A\&E department, patients in the more deprived group were less likely to be managed by an A\&E consultant $\left(30.1 \%\right.$ to $\left.34.5 \%, \chi^{2}=5.3, p=0.021\right)$ and waited on average an extra six and a half minutes to be seen by a doctor in A\&E (mean time (CI): more deprived 9.6 (8.6 to 10.6) minutes, less deprived 15.8 (13.8 to 17.9) minutes). Forty five per cent (448) of patients who were GCS $\leqslant 8$ on admission were intubated in A\&E. There was no significant difference in intubation rates between more and less deprived patients.

\section{Discharge from A\&E and transfers}

Patients in the more deprived group were more likely than those in the less deprived group to be discharged directly to a ward from A\&E $\left(46 \% v 35.6 \%, \chi^{2}=27.7, p=0.000\right)$. Fewer patients in the more deprived group went directly to the intensive therapy unit (ITU) $\left(7.8 \% \quad v \quad 13.5 \%, \chi^{2}=19.1\right.$, $\mathrm{p}=0.000)$ or theatre $\left(2.3 \% \vee 8.4 \%, \chi^{2}=36.5, \mathrm{p}=0.000\right)$. There was no significant difference in the proportion of patients transferred directly to the regional neurosurgical service from A\&E (40.2\% v 37.1\%). However, when late transfers to the neurosurgical service were considered, a higher proportion of more deprived patients were transferred to the service $\left(61.1 \% \vee 55.8 \%, \chi^{2}=6.8, \mathrm{p}=0.01\right)$. Similar proportions of more deprived $(3.1 \%)$ and less deprived $(3.4 \%)$ patients died in $A \& E$.

\section{Pre-existing disease}

There was no difference between more deprived and less deprived patients in terms of the presence of disease of the

Table 4 Logistic regression; the effect of deprivation category on survival

\begin{tabular}{lllll}
\hline Variables in the equation & B & Wald & df & p value \\
\hline Constant & 3.079 & 10.393 & 1 & 0.001 \\
Age & -0.050 & 100.027 & 1 & 0.000 \\
Type of injury & 1.261 & 4.613 & 1 & 0.032 \\
Pre-existing cardiovascular disease & 0.508 & 4.691 & 1 & 0.030 \\
Revised Trauma Score & 0.888 & 191.022 & 1 & 0.000 \\
Chest AIS & -0.188 & 7.924 & 1 & 0.005 \\
Abdominal AlS & -0.630 & 28.806 & 1 & 0.000 \\
Head AIS & -1.390 & 108.709 & 1 & 0.000 \\
Model $\chi^{2}$ & 755.385 & 0.000 & & \\
Hosmer Lemeshow test & 3.409 & 0.906 & & $\mathrm{p}$ value \\
\hline Variables not in the equation & Score & $\mathrm{df}$ & 0.313 & \\
\hline Sex & 1.017 & 1 & 0.338 & \\
Mechanism of injury & 5.681 & 5 & 0.394 & \\
Pre-existing respiratory disease & 0.728 & 1 & 0.925 & \\
Pre-existing disease of CNS & 0.009 & 1 & 0.277 & \\
Pre-existing diabetes & 1.181 & 1 & 0.265 & \\
Pre-existing renal disease & 1.241 & 1 & 0.204 & \\
Pre-existing malignancy & 1.616 & 1 & 0.862 & \\
Pre-existing alcoholism & 0.030 & 1 & 0.965 & \\
Pre-existing psychiatric disease & 0.002 & 1 & 0.393 \\
Pre-existing drug abuse problem & 0.730 & 1 & 0.281 & \\
Deprivation group & 1.160 & 1 & 0.645 & \\
Extremity AIS & 0.213 & 1 & & \\
\hline
\end{tabular}

All variables considered for inclusion in the logistic regression model are shown. Those variables for which the significance of the Wald statistic is $\leqslant 0.05$ were found to have a significant independent effect on mortality. $B$ is the weight given to variables in the logistic regression equation. The model $\chi^{2}$ and the Hosmer mortality. B is the weight given to variables in the logistic
Lemeshow test are tests of the goodness of fit of the model. 
Table 5 Summary of the differences between patients from more and less deprived areas

\begin{tabular}{|c|c|c|}
\hline & More deprived & Less deprived \\
\hline \multicolumn{3}{|l|}{ Injury mechanism } \\
\hline Assault & More common & \\
\hline Isolated head injury & More common & \\
\hline RTA & & More common \\
\hline High fall & & More common \\
\hline \multicolumn{3}{|l|}{ Injury severity } \\
\hline GCS on admission & Higher & \\
\hline \multicolumn{3}{|l|}{ Management } \\
\hline $\begin{array}{l}\text { Presentation out of hours } \\
\text { Alcohol or substance abuse }\end{array}$ & $\begin{array}{l}\text { More common } \\
\text { More common }\end{array}$ & \\
\hline $\begin{array}{l}\text { Transfers to neurosurgery } \\
\text { "Late transfers" }\end{array}$ & $\begin{array}{l}\text { No difference } \\
\text { More common }\end{array}$ & No difference \\
\hline Time to theatre (neurosurgery) & Slower & \\
\hline Time in ITU & & Longer \\
\hline Hospital stay & & Longer \\
\hline \multicolumn{3}{|l|}{ Survival } \\
\hline Univariate analysis & More likely & \\
\hline Multivariate & No difference & No difference \\
\hline
\end{tabular}

cardiovascular, respiratory, or central nervous systems, diabetes, renal disease, cancer, or psychiatric problems. Patients from more deprived areas were more likely to have a history of alcohol $\left(24.5 \% v 15.8 \%, \chi^{2}=17.1, \mathrm{p}=0.000\right)$ or substance abuse $\left(6.1 \% \vee 2.1 \%, \chi^{2}=17.5, \mathrm{p}=0.000\right)$.

\section{Theatre}

Of those patients who required surgical intervention, more deprived patients were more likely than less deprived patients to undergo neurosurgery as their first operation $(66.1 \% v$ $52.8 \%, \chi^{2}=18, p=0.000$ ). Approximately $80 \%$ of neurosurgical procedures take place outwith "normal" working hours (Mon-Fri 9 am-5 pm) regardless of deprivation status. The mean time to neurosurgical procedure for more deprived patients was 13 hours 31 minutes compared to 10 hours 42 minutes for less deprived patients $(\mathrm{F}=7.039, \mathrm{p}=0.008)$. This difference was not apparent when only direct transfers to the regional neurosurgical service from A\&E were considered; the mean time to neurosurgical procedure for more deprived patients was 9 hours 38 minutes and the mean time for less deprived patients was 8 hours 7 minutes ( $\mathrm{F}=2.442$, $\mathrm{p}=0.119)$.

\section{ITU and length of stay}

Patients from more deprived areas were less likely to spend time in ITU $\left(12.1 \% v 24.2 \%, \chi^{2}=54, \mathrm{p}=0.000\right)$ and had significantly shorter ITU stays (median 2 days $v 3$ days, $\mathrm{p}=0.032$ ). Of those patients who survived to discharge, median length of hospital stay for the more deprived patients was significantly shorter ( 9 days) than for the less deprived patients ( 12 days, $\mathrm{U}=493242, \mathrm{p}=0.000$ ).

\section{Outcome}

Overall, more deprived patients were more likely to survive than less deprived patients $(81.2 \% \vee 78 \%, \mathrm{p}=0.046)$. Logistic regression showed that deprivation had no independent effect on survival following head injury (table 4).

\section{Summary}

Table 5 summarises salient differences between patients from more and less deprived areas.

\section{DISCUSSION}

To our knowledge this is the first study to assess the relation between social deprivation and head injury in adults using prospectively collected population based data. Trauma admissions fulfilling STAG criteria were more common among individuals from more deprived areas and within this trauma population head injury was more common among those from more deprived areas. This is in accord with other studies from other geographical areas and using other measures of social deprivation in both adults and children. ${ }^{6} 8918$

After adjusting for other recognised predictors of mortality, we have not found any evidence that social deprivation is an independent predictor of mortality following head injury in adults admitted to hospital or that patients from deprived areas had more severe injuries or that patients from more deprived areas had more severe injuries. These results contrast with those of Whitman and colleagues' Chicago Study ${ }^{9}$ and Wagner and colleagues' study in Carolina ${ }^{19}$ where mortality rates and injury severity were found to be higher in an inner city community, among blacks and among those of minority status. The discrepancy may be explained by the confounding of ethnicity and deprivation in Whitman and colleagues' study together with a failure to adjust for injury mechanism and severity. Of particular note is the high incidence of penetrating trauma, particularly firearm injuries, among the more deprived groups in these studies. Such injuries are very rare in the Scottish trauma population. Kraus and colleagues, ${ }^{20}$ in their study of residents in San Diego County, also described a higher incidence of firearm injuries among those with lower median family income. Median family income did not influence mortality in Kraus and colleagues' study, a result in keeping with the findings of the current study. Our findings in adults also differ from published findings in children. ${ }^{78}$ Both these studies suggested higher mortality from head injury in children from more deprived areas, although injury severity and mechanism were not explicitly adjusted for.

There were notable differences in pattern and type of injury and in management following admission to hospital between individuals from more and less deprived areas in our study. Patients from more deprived areas were more likely to have sustained their injury as the result of an assault and less likely to have been involved in a road traffic accident or to have suffered a fall from a height. Consistent with these differences in injury mechanism, patients from more deprived areas more commonly suffered an isolated head injury, had a higher median GCS on admission, and more frequently had evidence of normal physiology on admission. The observed early management differences are also explicable in terms of different injury mechanisms and severity. Thus more patients from deprived areas presented "out of hours", fewer were triaged to the resuscitation room on admission, they were less likely to be treated by a consultant in A\&E, and they waited slightly longer to be seen by a doctor following admission. Similar proportions of patients from more and less deprived areas with admission GCS $\leqslant 8$ were intubated in the A\&E department and similar proportions were transferred to the relevant regional neurosurgical units. This suggests that differences in early management are probably related to differing injury severity and mechanism. More patients from deprived areas were transferred to the regional neurosurgical unit at a later stage (defined as a transfer from a hospital ward rather than the A\&E department) and in these patients, the time from hospital admission to neurosurgical theatre was longer. This group is likely to comprise patients who showed a delayed deterioration following admission to hospital or in whom clinical assessment was confounded by alcohol or other substance use. Indeed, a history of alcohol and substance use was more common in individuals from more deprived areas. Time spent in the ITU and overall length of hospital stay were less in patients from more deprived areas and this too is in keeping with less severe initial injuries and a lower incidence of extracranial injuries in this group.

We have used the Carstairs index ${ }^{13}$ as a measure of social deprivation. This is a measure of area rather than individual deprivation and is therefore partly dependent on the ways in which areas are defined and partly on the homogeneity or heterogeneity of the populations within them with respect to 
the variables measured. It is possible therefore that we may have failed to detect a relation between head injury mortality and deprivation measured using the Carstairs index that would have been apparent if a different measure of individual deprivation had been used. We think this is unlikely given previous reports that have related other health outcome measures to deprivation assessed using the Carstairs index. ${ }^{151821} \mathrm{~A}$ potential source of bias is the absence of postcode information in roughly $7 \%$ of the study population. We have addressed this problem by assuming that all those with missing postcode information were from the most deprived areas, and repeating the analysis. Even under this assumption there is no independent effect on mortality.

We have used mortality as an outcome measure. It has the advantages of being relatively easily determined and unambiguous. It may however lack the sensitivity of other measures such as the Glasgow Outcome Scale ${ }^{22}$ and the Disability Rating Scale, ${ }^{23}$ and does not take account of the major burden of disability among survivors of head injury. ${ }^{24}$ The lack of a relation between mortality and social deprivation may not hold true for these other measures of outcome.

Definition and coding of head injury and case ascertainment have been recurring problems in previous studies of head injury epidemiology. ${ }^{25}$ We have used the AIS score for the head to identify patients within the STAG database that have sustained a head injury. This is an objective and precisely defined indicator of head injury. A single individual with specific training in the coding methodology performed all coding within the database. Data in the database were collected prospectively and it is estimated that STAG captured in excess of $94 \%$ of all eligible trauma cases in Scotland during the study period. Data collection and data entry is subject to detailed quality assurance checks. The study population therefore represents an accurate picture of head injury (as defined for the purposes of the study) in adults in Scotland during the study period. However, it should be noted that STAG does not capture all head injuries presenting to A\&E departments in Scotland. A large number of patients with less severe injuries are either discharged from A\&E or admitted for a period of less than three days. ${ }^{24}$ These patients are not captured by the STAG audit and the findings of the current study are not necessarily generalisable to this group.

\section{Conclusions}

We found no evidence of an independent effect of social deprivation on mortality in adults admitted to hospital with head injury in Scotland. There were consistent differences in injury mechanism, injury severity, and pattern of care between patients from more and less deprived areas. It is important to take account of such differences before attributing difference in outcome to the effects of social deprivation per se.

\section{Authors' affiliations}

L Dunn, Department of Neurosurgery, University of Glasgow, Glasgow G12 8QQ, UK

J Henry, D Beard, Scottish Trauma Audit Group (STAG), Royal Infirmary of Edinburgh, Edinburgh EH3 9YW, UK
Funding: STAG is one of four national audits whose funding is currently administered by the Common Services Agency in Scotland

\section{REFERENCES}

1 McLoone P. Carstairs scores for Scottish postcode sectors from the 1991 census. Glasgow: University of Glasgow, 1994.

2 McKinney PA, Feltbower RG, Parslow RC, et al. Survival from childhood cancer in Yorkshire, UK: Effect of ethnicity and socio-economic status. Eur J Cancer 1999;35:1816-23.

3 Schrijvers CTM, Mackenbach JP, Lutz J-M, et al. Deprivation and survival from breast cancer. Br J Cancer 1995;72:738-43.

4 Murray CJL, Lopez AD. Mortality by cause for eight regions of the world: Global Burden of Disease Study. Lancet 1997;349:1269-76.

5 Stark AD, Bennet GC, Stone DH, et al. Association between childhood fractures and poverty: population based study. BN 2002;324:457.

6 Cubbin C, LeClere F, Smith GS. Socioeconomic status and the occurrence of fatal and nonfatal injury in the United States. Am J Public Health 2000;90:70-7

7 Williamson LM, Morrison A, Stone DH. Trends in head injury mortality among 0-14 year olds in Scotland (1986-95). J Epidemiol Community Health 2002;56:285-8.

8 Sharples PM, Storey A, Aynsley-Green A, et al. Causes of fatal childhood accidents involving head injury in Northern Region, 1976-1986. BM 1990:301:1193-7.

9 Whitman S, Coonley-Hoganson R, Desai BT. Comparative head trauma experiences in two socioeconomically different Chicago-area communities: a population study. Am J Epidemiol 1984;119:570-80.

10 Kraus JF. Epidemiology of head injury. In: Cooper PR, ed. Head injury. Baltimore: Williams Wilkins, 1993

11 Rockett IRH, Smith GS. Injuries in relation to chronic disease: an international view on premature mortality. Am J Public Health 1987:77:1345-6.

12 Beard D, Henry JM, Grant PT. National audit of the management of injured patients in 20 Scottish hospitals. Health Bull 2000;58:1 18-26.

13 Carstairs V, Morris R. Deprivation and health in Scotland. Aberdeen: Aberdeen University Press, 1992

14 Yates DW, Woodford M, Hollis S. Preliminary analysis of the care of injured patients in 33 British hospitals: first report of the United Kingdom major trauma outcome study. BM 1992;305:737-40.

15 Medicine AAfA. The Abbreviated Injury Scale, 1985 revision. Arlington Heights, IL: AAAM, 1985

16 Morris R, Carstairs V. Which deprivation? A comparison of selected deprivation indexes. J Public Health Med 1991:13:318-26.

17 McLoone P, Boddy FA. Deprivation and mortality in Scotland, 1981 and 1991. BN 1994;309:1465-70.

18 Morrison A, Stone DH, Redpath A, et al. Trend analysis of socioeconomic differentials in deaths from injury in childhood in Scotland, 1981-1995. BM 1999;318:576-68.

19 Wagner AK, Sasser HC, Hammond FM, et al. Intentional traumatic brain injury: epidemiology, risk factors, and associations with injury severity and mortality. J Trauma 2000;49:404-10.

20 Kraus JF, Fife D, Ramstein K, et al. The relationship of family income to the incidence, external causes and outcomes of serious brain injury, San Diego County, California. Am J Public Health 1986;76:1345-7.

21 McEntegart A, Mossison E, Capell HA, et al. Effect of social deprivation on disease severity and outcome in patients with rheumatoid arthritis. Ann Rheum Dis 1997;56:410-13.

22 Pettigrew LE, Wilson JT, Teasdale GM. Assessing disability after head injury: improved use of the Glasgow Outcome Scale. J Neurosurg 1998;89:939-43.

23 Hall K, Cope DN, Rappaport M. Glasgow Outcome Scale and Disability Rating Scale: comparative usefulness in following recovery in traumatic head injury. Arch Phys Med Rehabil 1985;66:35-7.

24 Thornhill S, Teasdale GM, Murray GD, et al. Disability in young peoples and adults one year after head injury: prospective cohort study. BM 2000;320:1631-5

25 Jennett B. Epidemiology of head injury. J Neurol Neurosurg Psychiatry 1996:60:362-9. 